\title{
Development and evaluation of an early detection intervention for mouth cancer using a mass media approach
}

\author{
D Eadie",', AM MacKintosh', S MacAskill' and A Brown' \\ 'Centre for Tobacco Control Research, University of Stirling and The Open University, Stirling FK9 4LA, UK
}

\begin{abstract}
BACKGROUND: Scotland has a high incidence of mouth cancer, but public awareness and knowledge are low compared with other cancers. The West of Scotland Cancer Awareness Project sought to increase public awareness and knowledge of mouth cancer and to encourage early detection of symptoms among an at-risk population of people aged over 40 years from lower socio-economic groups using a mass media approach. The media campaign aimed to increase people's feelings of personal risk, while also enhancing feelings of efficacy and control. To achieve this, a testimonial approach (using real people to tell their own stories) was adopted. METHODS: Campaign impact and reach was assessed using in-home interviews with a representative sample of the target population in both the campaign area and controls outside of the target area. Surveys were conducted at three stages: at baseline before the campaign was launched, and at 7 and 12 months thereafter.

RESULTS: Awareness of media coverage was higher at both follow-up points in the intervention area than in the control area, the differences largely being accounted for by television advertising. The campaign had a short-term, but not a long-term impact on awareness of the disease and intention to respond to the symptoms targeted by the campaign. Awareness of two of the symptoms featured in the campaign (ulcers and lumps) increased, post-campaign, among the intervention group.

CONCLUSIONS: While the study provides evidence for the effectiveness of the self-referral model, further work is needed to assess its ability to build public capacity to respond appropriately to symptoms and to compare the cost-effectiveness of a mass media approach against alternative communication approaches and more conventional mass screening. British Journal of Cancer (2009) I 0 I, S73-S79. doi:I0.1038/sj.bjc.6605395 www.bjcancer.com
\end{abstract} (c) 2009 Cancer Research UK

Keywords: mouth cancer; early detection; mass media; evaluation

Mouth cancer is defined as cancers of the lip, tongue, oral cavity, oropharynx, hypopharynx and piriform sinus. Globally, mouth cancer is the 12th most common malignant tumour. In the United Kingdom, $\sim 5300$ people are diagnosed with mouth cancer each year and about half of those will die from the disease. Scotland has a higher incidence of mouth cancer than any other country in the United Kingdom: over 600 new cases are diagnosed each year (Office for National Statistics, 2009). Epidemiological data suggests a clear link between smoking, heavy drinking and deprivation and the onset of mouth cancer. In addition, mouth cancer is most common in older people, with $86 \%$ of cases occurring in people over the age of 50 years (Office for National Statistics, 2009).

Research suggests that survival rates could be improved by up to $30 \%$, and quality of life enhanced, if people present with early symptoms of the disease (Schrijvers et al, 1995). Many precancerous malignancies can be detected by physical inspection of the mouth. However, nearly two in five $(38.7 \%)$ of adults in Scotland are not registered with a dentist, with registration rates declining sharply above the age of 55 years (ISD, 2009). Furthermore, public awareness of the disease and its symptoms is poor. An unpublished survey conducted by Market Research UK in 2001 revealed that only $6 \%$ of adults in the west of Scotland were

\footnotetext{
*Correspondence: Dr D Eadie; E-mail: douglas.eadie@stir.ac.uk
}

aware of mouth cancer (unprompted) and 54\% were unable to name a single symptom. These findings are consistent with those found in other population studies (Cruz et al, 2002; Hay et al, 2002; Horowitz et al, 2002; West et al, 2006).

It is speculated that infrequent coverage of mouth cancer in the popular media may help to explain the public's lack of knowledge about the disease. Although cancer receives a large amount of media attention, coverage tends to emphasise cancer deaths and treatment in preference to prevention and early detection (Signorielli, 1990), and it also gives certain cancers, most notably breast cancer, greater coverage (Marino and Gerlach, 1999). In contrast, low media coverage of mouth cancer helps to explain poor public awareness and understanding of the disease in the United States. A 10-year study of newspaper and magazine coverage of mouth cancer in the United States found only 50 articles and news items on mouth cancer (Canto et al, 1998). While the majority of these articles mentioned at least one-risk factor, only half made any reference to symptoms of the disease and substantially fewer suggested visiting a health professional for advice.

The strong evidence base for the ability of media campaigns to promote improvements in health awareness and knowledge (Campion et al, 1994; Hafstad et al, 1997) and to increase participation rates in mass screening programmes (Gregorio et al, 1990; Shelley et al, 1991) has focussed attention on the potential to combine these strengths in campaigns promoting the early 
detection of disease. While mass screening programmes are aimed at all members of the at-risk population, early detection aims to encourage only those who experience relevant disease symptoms to self-present to an appropriate health professional for advice and possible onwards referral to specialist diagnostic and treatment services. However, unlike mass screening, the effectiveness of early detection depends on raising public awareness of the symptoms and equipping people with the ability to identify the symptoms and respond appropriately.

This paper reports on the development and evaluation of a mass media intervention to increase awareness, knowledge and early detection for mouth cancer in the west of Scotland. The West of Scotland Cancer Awareness Project (WoSCAP) was targeted at an at-risk population of people aged 40 years and over from lower socio-economic groups across the west of Scotland. The primary aim of the campaign was to encourage people to present to a local general dental practitioner if they experienced symptoms that might indicate the early onset of mouth cancer. The campaign's impact on patient presentation to primary healthcare teams will be reported separately. The campaign, the first of its kind in the United Kingdom, brought together five local regional health boards with a combined population of over 2.5 million, nearly half of Scotland's entire population. The partnership between the health boards offered a number of structural and economic benefits, most notably increased media buying power, access to regional broadcast networks and continuity with centralised treatment services.

A key challenge facing the media campaign was the need to increase public awareness of personal risk and perceived susceptibility, while at the same time avoiding raising unnecessary anxiety and encouraging inappropriate self-referrals from the so-called 'worried well'. Given the experimental nature of the campaign, there was a deeply felt concern among service planners and providers that a failure to meet demand for diagnostic services could lead to unacceptable delays for those requiring treatment. Consequently, the campaign was grounded in social marketing to ensure campaign development was consumer led and founded on sound communication principles. This involved precise targeting of the at-risk population using formative research and pre-testing techniques to guide the campaign message, tone, imagery, language, etc. (Eadie and Smith, 1995). As an additional safeguard, local monitoring procedures were set in place to ensure that the media schedule could be modified at short notice to moderate demand for diagnostic services.

Careful consideration was also given to the campaign media strategy and channel selection in terms of reach, message delivery and integration with other programme components. There is substantial evidence that people in low-income groups and with lower educational attainment display above average levels of television viewing and radio listening (Social Trends, 1995; Anderson et al, 1989). Other research has shown print media to be effective at communicating detailed factual information about cancer (Humphris et al, 2001), and direct mail campaigns to be a particularly cost-effective method for encouraging low-income groups to attend for cancer screening (Sugg-Skinner et al, 1994). There is also substantial evidence that awareness campaigns, which adopt a multi-faceted approach, for example, combining paid and unpaid media and interpersonal components, reinforce and amplify one another and combine to produce a greater and longer-lasting effect (Fortmann et al, 1995; Pentz et al, 1997). This evidence base led to an integrated media strategy combining two 40-second advertisements, one on television and the other on local radio, supported by free wall posters, leaflets and direct mail leaflet drops in key target communities. In addition, the project also worked closely with the media to generate news coverage in local and national press and by broadcast media. The total cost of the campaign, including public relations activity, was $£ 264000$.

\section{Campaign theory}

The WoSCAP campaign goals and message strategy were established using social cognitive theory (Bandura, 1977, 1986), which defines human behaviour as being reciprocally determined by personal factors (such as knowledge, skills, self-efficacy, outcome expectations and personal goals) and environmental factors (such as social and institutional norms, and physical environment). A review of the existing evidence base and exploratory research conducted with the target group identified three personal factors responsible for discouraging patients to come forwards for help and advice: poor knowledge, low perceived risk and fear of negative health outcomes, such as being diagnosed with the disease and concerns over effectiveness of treatment.

These factors were critical to setting the campaign goals and the means by which each might be achieved: to raise awareness of the disease and methods of early detection and to trigger help-seeking behaviour. The first goal was an important precursor to action and played to one of the main strengths of media-based communication - the ability to increase audience awareness and knowledge. However, the second goal, developing a persuasive message strategy, presented a particular challenge - to increase people's feelings of personal risk while, at the same time, enhancing feelings of efficacy and control. A means had to be found of bringing these two motivational themes together in a way that was both credible and persuasive. The existing evidence highlights the risks to using overt fear appeals and their ability to evoke maladaptive responses such as avoidance and distortion (Tanner et al, 1991; Schoenbachler and Whittler, 1996; Witte et al, 1998). Given the fatalism and very real sensitivities that characterised people's feelings about personal intervention and secondary forms of cancer prevention, there was a real risk that using overt fear appeals would undermine any attempts to boost people's confidence to respond proportionately. Instead, the campaign turned to social cognitive theory for a possible solution.

Social cognitive theory proposes that much behaviour is learned from observing the actions of others and the consequences for them, and suggests that the acquisition of new patterns of behaviour can be accelerated by 'modelling' the desired behaviour, that is using real people to either explain or show through action how they made the behaviour change (Bandura, 1977, 1986). Sutton et al (1995) suggest that social modelling helps the individual master the behaviour and provides them with the confidence to make the change. Formative research carried out with members of the target audience found support for a testimonial approach, using real people to describe in their own terms their symptoms, their responses and the consequences of their actions. The testimonial approach offers a number of benefits. For example, using ordinary people who tell their own stories allows the target audience to identify more directly with the problem, and to reassess the significance of what could be dismissed as relatively innocuous everyday ailments. In this way, the approach provides normative support for the idea of looking out for the early symptoms of the disease. In addition, by selecting personal testimonies, which not only illustrate the positive health outcomes of responding promptly to the symptoms, but also the negative outcomes of failing to respond, the approach provides a credible means of combining the potentially discordant motivational themes of self-efficacy and personal risk.

In addition to influencing personal factors, the WoSCAP campaign also sought to influence environmental factors by using paid advertising to leverage news coverage and local briefing events to encourage primary healthcare professionals to carry the campaign message to key patient populations. In this way, the campaign sought to influence media and institutional environments to build word-of-mouth communication and to raise the level and standard of public debate around the issue. 


\section{MATERIALS AND METHODS}

A three-stage cross-sectional tracking survey with control was conducted to monitor campaign reach (e.g. awareness and response to individual campaign elements) and communication effect (e.g. impact of the campaign on knowledge of early symptoms and propensity to self-refer). A baseline survey was conducted before the launch of the media campaign, with a first follow-up survey 7 months later immediately after the main burst of media activity and a second follow-up completed a further 12 months after that.

Intervention and control samples were selected using a random location quota methodology to be broadly representative of the campaign's target audience: adults aged 40-70 years from social classes C1, C2, D and E. Respondents were recruited on the basis of meeting the socio-demographic requirements and living in postcode sectors with high social disadvantage ratings. A sample of 80 postcode sectors was drawn from non-rural localities within eight health board areas, 50 postcode sectors from the five health boards participating in the campaign and the remaining 30 postcode sectors from three health boards that made up the control area. Within each of the intervention and control areas, postcode sectors were randomly selected with probability proportionate to size and were stratified by health board and disadvantage score. Both samples were drawn from private households within the selected postcode sectors.

Both surveys were administered using face-to-face in-home interviewing techniques and were conducted by a team of professional market research interviewers. Interviewers were assigned a quota of 12 interviews and instructed to obtain a minimum of 10 interviews in each of the 80 allocated areas (target sample 800 interviews). The quota was interlocked on age, sex and social class. A total of 922,934 and 944 completed interviews were achieved at baseline and first and second follow-up, respectively (Table 1).

The target sample within each of the quota categories was achieved; additional interviews tended to be with female and older respondents and were retained within the survey. Although the sample profile has a higher proportion of females and older respondents than intended, the profiles of the intervention and control samples did not differ.

The exclusion of rural areas and the reliance on non-probability sampling methods means that this sample cannot be said to be completely representative of, or absolutely predictive for, the target population. The sample is, however, large enough to be strongly indicative of the complete target population. It is, therefore, useful to examine the pattern of the results and conduct statistical tests to gain an understanding of the sample as if it were generated by a random selection process.

Within each survey wave, logistic regression has been used to examine differences by intervention status, while controlling for age, gender, social grade, marital status, education level and experience of cancer. To enable interpretation of post-intervention results, where differences already existed at baseline, logistic regression was run with all three survey waves and incorporated a survey stage by intervention status interaction term. A significant interaction term provided an indication that intervention and control samples displayed different patterns across survey waves. If the interaction term was not significant, this indicated that, after controlling for baseline differences, there was no impact from the intervention.

\section{RESULTS}

The results are organised by media coverage of mouth cancer, awareness and perceived incidence of the cancer, awareness of mouth cancer symptoms, salience of mouth cancer symptoms and intention to respond to symptoms of mouth cancer.

\section{Media coverage}

To provide a context for understanding the campaign's impact on awareness and knowledge of the disease, respondents who had heard of mouth cancer were asked whether or not they had come across media coverage about it from a range of sources (see Table 2). Awareness of any source of media coverage was higher, at baseline and both follow-up surveys, among the intervention sample compared with the control sample $(27$ vs $20 \%(P<0.01), 80$ vs $26 \%(P<0.001)$ and 40 vs $14 \%(P<0.001)$, respectively). After controlling for the difference at baseline, the post-campaign differences between intervention and control samples remained significant. Television advertising largely accounted for the media coverage $(74$ vs $11 \%(P<0.001)$ and 30 vs $3 \%(P<0.001))$ at first and second follow-up, respectively. At the first and second followup, fewer than $10 \%$ of respondents in the intervention area cited each of the other media, newspapers, radio, poster or booklets/ leaflets, as sources of media coverage.

The results also revealed differences in media coverage over time with awareness of any media source increasing between baseline and first follow-up, rising from $27 \%$ to $80 \%$ in the intervention area and then falling back to $40 \%$ by second follow-up. These differences were again attributed in large part to television advertising (the campaign's primary medium),

Table I Sample characteristics by gender, age and socio-economic status

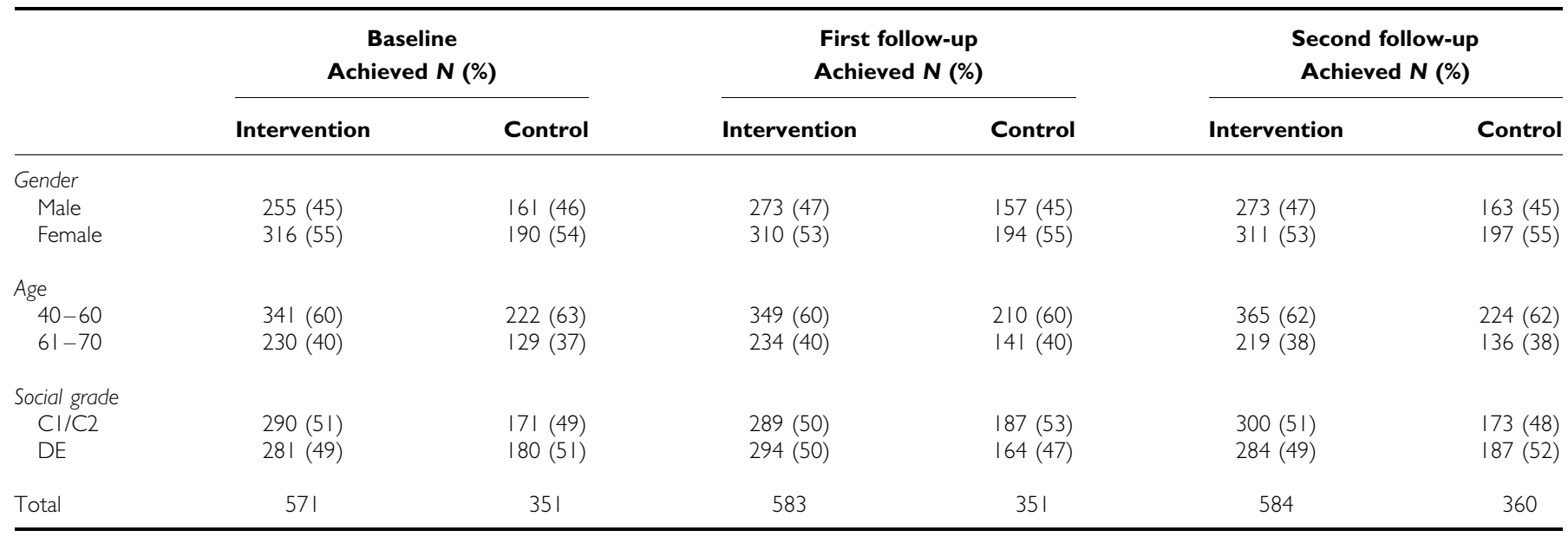


Table 2 Media coverage about mouth cancer in the last 6 months

\begin{tabular}{|c|c|c|c|c|c|c|}
\hline \multirow[b]{2}{*}{$\begin{array}{l}\text { Base: all who have } \\
\text { heard of mouth cancer }\end{array}$} & \multicolumn{2}{|c|}{ Baseline } & \multicolumn{2}{|c|}{ First follow-up } & \multicolumn{2}{|c|}{ Second follow-up } \\
\hline & $\begin{array}{l}\text { Intervention } \\
\text { area (469) \% }\end{array}$ & $\begin{array}{c}\text { Control } \\
\text { area (28I) \% }\end{array}$ & $\begin{array}{l}\text { Intervention } \\
\text { area (536) \% }\end{array}$ & $\begin{array}{c}\text { Control } \\
\text { area }(300) \%\end{array}$ & $\begin{array}{l}\text { Intervention } \\
\text { area (5 I 2) \% }\end{array}$ & $\begin{array}{c}\text { Control } \\
\text { area }(3 \mid 5) \%\end{array}$ \\
\hline Any source & $27 * *$ & 20 & $80 * * * *$ & 26 & $40 * * * *$ & 14 \\
\hline TV advertisements & 2 & 3 & $74 * * *$ & $\mid 1$ & $30 * * *$ & 3 \\
\hline Newspapers & 2 & 4 & 7 & 3 & $5 * *$ & 2 \\
\hline Radio & $<1 \%$ & 1 & 3 & I & $3 *$ & $<1 \%$ \\
\hline Poster & 5 & 4 & $8 * *$ & 2 & 6* & 3 \\
\hline Booklets/leaflets & 4 & 2 & $9 * *$ & 3 & 5 & 4 \\
\hline
\end{tabular}

Logistic regression testing for differences by intervention status within each survey wave, controlling for gender, age, social class, marital status, education and experience of cancer. Differences are noted as follows: $* P<0.05$, *** $P<0.01$, **** $P<0.001$.

Table 3 Prompted awareness of various cancers

\begin{tabular}{|c|c|c|c|c|c|c|}
\hline \multirow[b]{2}{*}{$\begin{array}{l}\text { Base: } \\
\text { all respondents }\end{array}$} & \multicolumn{2}{|c|}{ Baseline } & \multicolumn{2}{|c|}{ First follow-up } & \multicolumn{2}{|c|}{ Second follow-up } \\
\hline & $\begin{array}{l}\text { Intervention } \\
\text { area }(571) \%\end{array}$ & $\begin{array}{c}\text { Control } \\
\text { area }(35 I) \%\end{array}$ & $\begin{array}{l}\text { Intervention } \\
\text { area (583) \% }\end{array}$ & $\begin{array}{c}\text { Control } \\
\text { area (35I) \% }\end{array}$ & $\begin{array}{l}\text { Intervention } \\
\text { area (584) \% }\end{array}$ & $\begin{array}{c}\text { Control } \\
\text { area }(360) \%\end{array}$ \\
\hline Stomach cancer & 90 & 87 & 90 & 91 & 91 & 90 \\
\hline Cervical cancer & 91 & 89 & 91 & 89 & 89 & 91 \\
\hline Testicular cancer & 87 & 88 & 88 & 86 & 89 & 90 \\
\hline Mouth/mouth cancer & 82 & 80 & $92 * *$ & 85 & 88 & 88 \\
\hline Ovarian cancer & 84 & 84 & 85 & 83 & 86 & 90 \\
\hline Bladder cancer & 61 & 58 & 65 & 65 & $69 *$ & 64 \\
\hline Bowel cancer & 96 & 97 & 97 & 98 & 97 & 97 \\
\hline Breast cancer & 99 & 98 & 99 & 99 & 99 & 99 \\
\hline Lung cancer & 99 & 100 & 98 & 98 & 98 & 97 \\
\hline Prostate cancer & 92 & 93 & 94 & 96 & 95 & 96 \\
\hline Skin cancer & 97 & 97 & 97 & 97 & 97 & 96 \\
\hline
\end{tabular}

Logistic regression testing for differences by intervention status within each survey wave, controlling for gender, age, social class, marital status, education and experience of cancer. Differences are noted as follows: $* P<0.05$, $* * P<0.01$.

which peaked at $74 \%$ at first follow-up and then fell to $30 \%$ by second follow-up. These figures provide a reliable measure of campaign recall as no other mouth cancer prevention campaigns using television advertising were running at the time of exposure.

Among the intervention sample prompted, awareness of the TV advertisement was $83 \%$ at the first follow-up and $69 \%$ at the second follow-up. A substantial proportion of the control sample also indicated awareness of the TV advertisement with $23 \%$ aware at the first follow-up and $25 \%$ aware at the second follow-up.

\section{Awareness and perceived incidence of mouth cancer}

Respondents were asked to name cancers that they had heard of. They were then given a list of up to 11 cancers and, for each one that they had not already mentioned, were asked whether or not they had heard of it. Table 3 shows awareness of each. Awareness of most cancers was high, $80 \%$ or more and there were no differences by intervention status at baseline. At the first followup, mouth cancer was the only one which differed by intervention status, with intervention respondents having higher awareness (92 vs $85 \% ; P<0.01$ ). However, this difference was not maintained at the second follow-up, suggesting that the campaign may have had a short-term effect on awareness of the disease.

A measure of the perceived incidence was also taken for 9 of these 11 cancers (Table 4), by asking respondents how rare or common they thought each cancer was in Scotland. Answers were given on a five-point scale ranging from 1 (very rare) to 5 (very common). Breast and lung cancer had the highest perceived incidence with over $80 \%$ of respondents considering these cancers to be very or quite common. Mouth cancer (23\% intervention vs
$12 \%$ control $(P<0.01)$ at baseline $)$ along with bladder cancer $(26 \%$ intervention vs $19 \%$ control $(P<0.05))$ had low perceived incidence relative to other cancers. Throughout all survey stages, intervention respondents were more likely than those from the control sample, to perceive mouth cancer to be very or quite common $(P<0.01)$. However, the pattern across time did not differ between intervention and control respondents, and, therefore, provided no indication that the campaign resulted in higher perceived incidence of mouth cancer.

An analysis of these same data by campaign awareness reveals differences for mouth cancer at first follow-up, with those aware of the campaign more likely than those unaware of the campaign, to consider mouth cancer to be very or quite common (26\% aware of TV ad $v s 15 \%$ not aware; $P<0.01)$. By the second follow-up, perceived incidence did not differ by awareness of the TV advertisement.

\section{Awareness of symptoms}

Understanding of mouth cancer and its detection was measured using an open-ended question, which asked respondents to describe in their own terms the symptoms of the disease. Table 5 describes the data to emerge from an analysis by intervention and control samples, differentiating between those symptoms highlighted by the campaign and those not highlighted.

For many of the symptoms highlighted by the campaign, intervention respondents at baseline were significantly more likely than their control respondents to mention these symptoms (sores, red or white patch, changes that persist and changes to the tongue). These statistically significant differences between intervention and control were also observed in the follow-up surveys. 
Table 4 Perceived incidence of cancer in Scotland - percent who consider each to be 'very/quite common'

\begin{tabular}{|c|c|c|c|c|c|c|}
\hline $\begin{array}{l}\text { Base: all respondents } \\
\% \text { who consider each } \\
\text { to be very/quite common }\end{array}$ & \multicolumn{2}{|c|}{ Baseline } & \multicolumn{2}{|c|}{ First follow-up } & \multicolumn{2}{|c|}{ Second follow-up } \\
\hline Lung cancer & 90 & 86 & 88 & 88 & 88 & 84 \\
\hline Breast cancer & 89 & 85 & 85 & 86 & 85 & 84 \\
\hline Prostate cancer & 61 & 63 & 63 & 68 & 66 & 62 \\
\hline Bowel cancer & $55 *$ & 61 & $51 * *$ & 61 & 54 & 57 \\
\hline Cervical & 60 & 57 & 56 & 55 & $60 *$ & 51 \\
\hline Stomach & $50 * *$ & 38 & 40 & 42 & $44 *$ & 36 \\
\hline Bladder & $26 *$ & 19 & 21 & 23 & $30 * *$ & 20 \\
\hline
\end{tabular}

Logistic regression testing for differences by intervention status within each survey wave, controlling for gender, age, social class, marital status, education and experience of cancer. Differences are noted as follows: $* P<0.05, * * P<0.01$.

Table 5 Symptom awareness

(a)

\begin{tabular}{|c|c|c|c|c|c|c|c|c|c|c|}
\hline \multirow[b]{3}{*}{ Base: all respondents } & \multicolumn{6}{|c|}{ (a) } & \multicolumn{4}{|c|}{ (b) } \\
\hline & \multicolumn{2}{|l|}{ Baseline } & \multicolumn{2}{|c|}{ First follow-up } & \multicolumn{2}{|c|}{ Second follow-up } & \multicolumn{2}{|c|}{$\begin{array}{c}\text { Prompted } \\
\text { awareness } \\
\text { of TV } \\
\text { campaign at } \\
\text { first follow-up }\end{array}$} & \multicolumn{2}{|c|}{$\begin{array}{c}\text { Prompted } \\
\text { awareness } \\
\text { of TV } \\
\text { campaign at } \\
\text { second follow-up }\end{array}$} \\
\hline & $\begin{array}{c}\text { Inter- } \\
\text { vention } \\
\text { area }(571) \%\end{array}$ & $\begin{array}{c}\text { Control } \\
\text { area } \\
(351) \%\end{array}$ & $\begin{array}{c}\text { Inter- } \\
\text { vention } \\
\text { area }(583) \%\end{array}$ & $\begin{array}{c}\text { Control } \\
\text { area } \\
(351) \%\end{array}$ & $\begin{array}{c}\text { Inter- } \\
\text { vention } \\
\text { area }(584) \%\end{array}$ & $\begin{array}{c}\text { Control } \\
\text { area } \\
(360) \%\end{array}$ & $\begin{array}{c}\text { Yes } \\
\text { (563) \% }\end{array}$ & $\begin{array}{c}\text { No } \\
\text { (37I) \% }\end{array}$ & $\begin{array}{c}\text { Yes } \\
(\mathbf{4 9 2 )} \%\end{array}$ & $\begin{array}{c}\text { No } \\
(452) \%\end{array}$ \\
\hline \multicolumn{11}{|l|}{ Symptoms highlighted by campaign } \\
\hline Ulcers & 35 & 31 & $53 * * *$ & 34 & $4 \mid * * * *$ & 30 & 55 ***** & 32 & $42 * * * *$ & 31 \\
\hline Sores & ।1* & 7 & $16 *$ & 11 & $15 * * *$ & 6 & 16 & 11 & $14 * *$ & 9 \\
\hline Red or white patch & 5 *** & I & $6 * * * *$ & I & 1 & $<1 \%$ & $6 * *$ & 2 & । & $<1 \%$ \\
\hline Spots & 4 & 3 & $\mid 4 * * *$ & 6 & 5 & 4 & $15 * * * *$ & 5 & 5 & 4 \\
\hline Lump(s) & 5* & 9 & 13 & 9 & 8 & 6 & $14 *$ & 8 & 9 & 5 \\
\hline Changes that persisted (any) & 6* & 3 & $22 * * * *$ & 11 & ||**** & 4 & $24 * * * *$ & 8 & $12 * * * *$ & 4 \\
\hline Pain & 19 & 17 & $12 *$ & 19 & 13 & 14 & $12 * *$ & 18 & 15 & 11 \\
\hline
\end{tabular}

Logistic regression testing for differences by (a) intervention status and (b) TV advertisement awareness within each survey wave, controlling for gender, age, social class, marital status, education and experience of cancer. Differences are noted as follows: $* P<0.05, * * P<0.0$ l, $* * * P<0.001$.

However, after controlling for the differences already present at baseline, there was no indication that awareness of these symptoms increased at a greater rate in the intervention areas. Therefore, there was no indication that the campaign resulted in higher mention of these symptoms. Awareness of ulcers and spots was equivalent at baseline. Ulcers had higher mention among intervention respondents at both follow-ups $(53$ vs $34 \%(P<0.001)$ and 41 vs $30 \%(P<0.001)$, respectively); and spots had higher mention at first follow-up $(14 v s 6 \%(P<0.001))$, suggesting that these mentions had been influenced by the campaign. Awareness of lumps was lower among intervention respondents at baseline $(P<0.05)$. At the first follow-up, mention of lumps did not differ significantly between intervention and control respondents, having increased among intervention respondents and having remained constant among control respondents. This increase was not maintained at the second follow-up, suggesting that the campaign had only a short-term influence on mention of lumps.

An analysis of these data by awareness of the campaign reveals that those who were aware of the campaign also have greater confidence and better knowledge of the symptoms targeted by the campaign than those who were unaware of the campaign (see Table 5). With three of the symptoms highlighted by the campaign, differences were observed between those aware and those who were unaware of the campaign at both first and second follow-up: persistent ulcers $(55$ vs $32 \%(P<0.001)$ and 42 vs $31 \%$ $(P<0.001))$, changes that persist $(24 v s 8 \%(P<0.001)$ and $12 v s$ $4 \%(P<0.001))$ and changes to the tongue $(15$ vs $7 \%(P<0.01)$ and 12 vs $5 \%(P<0.001))$. Three other symptoms highlighted by the campaign showed a difference, by campaign awareness, at first follow-up only: spots $(15$ vs $5 \%(P<0.001))$, lump(s) $(14$ vs $8 \%$ $(P<0.05))$ and a persistent red or white patch $(6 v s 2 \%(P<0.01))$. Of the two symptoms not highlighted by the campaign, bleeding and pain, the latter showed a difference at first follow-up, with those aware of the campaign less likely to identify pain as a symptom than those unaware of the campaign (12 vs $18 \%$ $(P<0.01))$.

\section{Salience of symptoms}

Measures of salience were taken for two symptoms of the disease targeted by the campaign, a persistent red or white patch in the mouth and a persistent ulcer or sore in the mouth (see Table 6). 
Table 6 Salience of specific symptoms - percent who would be 'very/quite concerned' if experienced the following symptoms

(a)

\begin{tabular}{|c|c|c|c|c|c|c|c|c|c|c|}
\hline \multirow[b]{2}{*}{ Base: all respondents } & \multicolumn{2}{|c|}{ Baseline } & \multicolumn{2}{|c|}{ First follow-up } & \multicolumn{2}{|c|}{ Second follow-up } & \multicolumn{2}{|c|}{$\begin{array}{c}\text { Prompted } \\
\text { awareness of } \\
\text { TV campaign } \\
\text { at first } \\
\text { follow-up }\end{array}$} & \multicolumn{2}{|c|}{$\begin{array}{l}\text { Prompted } \\
\text { awareness of } \\
\text { TV campaign } \\
\text { at second } \\
\text { follow-up }\end{array}$} \\
\hline & $\begin{array}{c}\text { Inter- } \\
\text { vention } \\
\text { area }(571) \%\end{array}$ & $\begin{array}{l}\text { Control } \\
\text { area } \\
(35 I) \%\end{array}$ & $\begin{array}{c}\text { Inter- } \\
\text { vention } \\
\text { area }(583) \%\end{array}$ & $\begin{array}{l}\text { Control } \\
\text { area } \\
(35 I) \%\end{array}$ & $\begin{array}{c}\text { Inter- } \\
\text { vention } \\
\text { area }(584) \%\end{array}$ & $\begin{array}{l}\text { Control } \\
\text { area } \\
(360) \%\end{array}$ & $\begin{array}{c}\text { Yes } \\
(563) \%\end{array}$ & $\stackrel{\text { No }}{(37 I)} \%$ & $\begin{array}{c}\text { Yes } \\
(492) \%\end{array}$ & $\begin{array}{l}\text { No } \\
(452) \%\end{array}$ \\
\hline $\begin{array}{l}\text { Persistent ulcer or sore in } \\
\text { the mouth }\end{array}$ & 70 & 65 & $77 *$ & 72 & $82 * * * *$ & 71 & $79 *$ & 69 & $81 * * *$ & 73 \\
\hline
\end{tabular}

Logistic regression testing for differences by (a) intervention status and (b) TV advertisement awareness within each survey wave, controlling for gender, age, social class, marital status, education and experience of cancer. Differences are noted as follows: $* P<0.05, * * P<0.01, * * * P<0.001$.

Table 7 Percent who would be 'very/moderately likely' to consult a GMP if experienced following symptoms

(a)

(b)

\begin{tabular}{|c|c|c|c|c|c|c|c|c|c|}
\hline \multicolumn{2}{|c|}{ Baseline } & \multicolumn{2}{|c|}{ First follow-up } & \multicolumn{2}{|c|}{ Second follow-up } & \multicolumn{2}{|c|}{$\begin{array}{c}\text { Prompted } \\
\text { awareness of } \\
\text { TV campaign } \\
\text { at first } \\
\text { follow-up }\end{array}$} & \multicolumn{2}{|c|}{$\begin{array}{l}\text { Prompted } \\
\text { awareness of } \\
\text { TV campaign } \\
\text { at second } \\
\text { follow-up }\end{array}$} \\
\hline $\begin{array}{c}\text { Inter- } \\
\text { vention } \\
\text { area }(571) \%\end{array}$ & $\begin{array}{l}\text { Control } \\
\text { area } \\
(351) \%\end{array}$ & $\begin{array}{c}\text { Inter- } \\
\text { vention } \\
\text { area }(583) \%\end{array}$ & $\begin{array}{l}\text { Control } \\
\text { area } \\
(351) \%\end{array}$ & $\begin{array}{c}\text { Inter- } \\
\text { vention } \\
\text { area }(584) \%\end{array}$ & $\begin{array}{l}\text { Control } \\
\text { area } \\
(360) \%\end{array}$ & $\begin{array}{c}\text { Yes } \\
\text { (563) \% }\end{array}$ & $\begin{array}{c}\text { No } \\
\text { (37I) \% }\end{array}$ & $\begin{array}{c}\text { Yes } \\
\text { (492) \% }\end{array}$ & $\begin{array}{c}\text { No } \\
\text { (452) \% }\end{array}$ \\
\hline 80 & 79 & 82 & 86 & $89 * * * *$ & 77 & 85 & 81 & $87 *$ & 81 \\
\hline 72 & 74 & 82 & 78 & $86 * * *$ & 77 & $83 *$ & 77 & $87 * *$ & 79 \\
\hline $42 *$ & 33 & 36 & 40 & $45 * * * *$ & 32 & 39 & 36 & $45 * *$ & 35 \\
\hline $42 * *$ & 31 & 31 & 35 & $43 * * * *$ & 29 & 33 & 31 & $42 * *$ & 32 \\
\hline
\end{tabular}

Base: all respondents

Very/moderately

likely to consult ...

... GMP

Persistent red or white patch in the mouth

Persistent ulcer or sore in the mouth

...Dentist

Persistent red or white patch in the mouth

Persistent ulcer or sore in the mouth

31

Logistic regression testing for differences by (a) intervention status and (b) TV advertisement awareness within each survey wave, controlling for gender, age, social class, marital status, education and experience of cancer. Differences are noted as follows: $* P<0.05$, $* * P<0.0$ I, *** $P<0.00$ I

At baseline, concern about each of the symptoms was the same for intervention and control respondents. At the first follow-up, concern about persistent ulcers or sores was higher among intervention respondents $(77$ vs $72 \%(P<0.05))$ and this was also the case at the second follow-up ( 82 vs $71 \%(P<0.001))$. Concern about persistent red or white patches in the mouth remained equal at the first follow-up, but, at the second follow-up, intervention respondents were more likely to indicate concern $(82 v s 69 \%(P<0.001))$. In both instances concern was also significantly higher among those aware of the TV advertisement at first and second follow-up.

\section{Behavioural intentions}

A measure of intention to act was also taken for the same two symptoms. Measures of actual behaviour were not viable as the proportion that experienced either symptom over the study period was extremely small $(1-2 \%)$. At baseline and the first follow-up, the likelihood of consulting a general medical practitioner (GMP) did not differ by intervention status. At the second follow-up, differences in intention to act between intervention and control were observed for both symptoms, with those in the intervention area significantly more likely to seek advice from a GMP than those in the control area (see Table 7). In the case of a persistent ulcer and sore, $86 \%$ of intervention respondents, compared with $77 \%$ of control respondents $(P<0.001)$ said that they would consult a GMP. The equivalent figures for a persistent red or white patch in the mouth were 89 vs $77 \%(P<0.001)$.

While most (over 70\%) respondents perceived it likely that they would consult a general practitioner, fewer than half (ranging from $29 \%$ to $45 \%$ ) considered it likely that they would consult a dentist (see Table 7). At baseline, intervention respondents indicated being more likely than control respondents to consult a dentist regarding either of these symptoms. By the first follow-up, both groups were equally likely to consult a dentist, with likelihood having decreased among intervention respondents as baseline. At the second follow-up, likelihood did not differ from that at baseline for either group. Therefore, there is no indication of the campaign having impacted on perceived likelihood of consulting a dentist about symptoms.

An analysis of these data was also carried out by campaign awareness (see Table 7). The findings reveal that those who were aware of the campaign were more likely to respond to the symptoms than those who were unaware of the campaign: a persistent red or white patch 87 vs $81 \%(P<0.05)$ at second followup, and a persistent ulcer or sore 83 vs $77 \%(P<0.05)$ at first follow-up and 87 vs $79 \%(P<0.01)$ at second follow-up. 


\section{DISCUSSION}

The results show that, even after controlling for differences at baseline and any potential influence of age, gender, social grade, marital status, education level and experience of cancer, postcampaign respondents in the intervention areas were more likely than control respondents to recall media coverage about mouth cancer, be aware of mouth cancer, recall specific symptoms featured in the campaign, be concerned about specific symptoms and indicate that they would consult a GMP about these symptoms. There was some contamination of the control respondents with $23 \%$ and $25 \%$ of the sample in the first and second follow-up, respectively, indicating awareness of the TV advertisement. As a result, it is possible that the evaluation underestimates the apparent impact of the campaign, given that some of the control sample may also be displaying signs of being influenced by the messages received. However, analysis by awareness of the TV advertisement showed that awareness of the advertisement was associated with higher awareness of symptoms of mouth cancer, increased concern about experiencing the symptoms and increased likelihood of consulting a GMP about such symptoms. Overall, the results suggest that the campaign has been successful in improving awareness of symptoms and encouraging concern and consideration of consulting a GMP should these symptoms be experienced.

Health care planners and clinicians are understandably wary of relying on mass media approaches to encourage patients to present to their GMP for advice about suspicious symptoms, fearing it could encourage inappropriate referrals and over-stretch diagnostic services. However, new learning from the development of the mouth cancer early detection campaign under investigation

\section{REFERENCES}

Anderson DM, Meissner HI, Portnoy B (1989) Media use and the health information acquisition process: how callers learned about the NCI's Cancer Information Service. Health Educ Res Theory Pract 4: 419-427

Bandura A (1977) Self-efficacy: toward a unifying theory of behavioral change. Psychol Rev 84: 191-215

Bandura A (1986) Social Foundations of Thought and Action: A Social Cognitive Theory. Prentice Hall: Englewood Cliffs, NJ

Campion P, Owen L, McNeill A, McGuire C (1994) Evaluation of a mass media campaign on smoking and pregnancy. Addiction 89: 1245-1254

Canto MT, Kawaguchi Y, Horowitz AM (1998) Coverage and quality of mouth cancer information in the popular press: 1987-1998. J Public Health Dent 58: $241-247$

Cruz GD, le Geros RZ, Ostroff JS, Hay JL, Kenigsberg H, Franklin M (2002) Mouth cancer knowledge, risk factors and characteristics of subjects in an mouth cancer screening program. J Am Dent Assoc 133: 1064-1071

Eadie DR, Smith CJ (1995) The role of applied research in public health advertising: some comparisons with commercial marketing. Health Educ J 54: $367-380$

Fortmann SP, Flora JA, Winkleby MA, Schooler C, Taylor CB, Farquhar JW (1995) Community intervention trials: reflections on the Stanford FiveCity Project experience. Am J Epidemiol 142: 576-586

Gregorio DI, Kegeles S, Parker C, Benn S (1990) Encouraging screening mammograms. Results of the 1988 Connecticut Breast Cancer Detection Awareness Campaign. Conn Med 54: 370-373

Hafstad A, Aarø LE, Engeland A, Andersen A, Langmark F, Pedersen-Stray F (1997) Provocative appeals in anti-smoking mass media campaigns targeting adolescents. The accumulated effect of multiple exposures. Health Educ Res 12: 227-236

Hay JL, Ostroff JS, Cruz GD, LeGeros RZ, Kenigsbert H, Franklin DM (2002) Mouth cancer risk perception among participants in an mouth cancer screening program. Cancer Epidemiol Biomarkers Prev 11: 155-158

Horowitz AM, Canto MT, Child WL (2002) Maryland adults' perspectives on mouth cancer prevention and early detection. J Am Dent Assoc 133: $1058-1063$

Humphris GM, Ireland RS, Field EA (2001) Immediate knowledge increase from an mouth cancer information leaflet in parents attending a primary health care facility: a randomised controlled trial. Oral Oncol 37: 99-102 suggests that applying social marketing principles and involving patient groups in the development of campaign materials can ensure the message strategy used takes full account of the sensitivities surrounding the issue. The results to emerge from this evaluation provide consistent evidence for the effectiveness of using mass media to raise awareness of the symptoms of the cancer and to encourage those at risk to self-refer to a health professional for advice and diagnosis in which appropriate.

Although this study shows the effectiveness of using the mass media to promote awareness of early detection for those cancers with pre-malignant symptoms, further work is need to compare the cost-effectiveness of the self-referral model with alternative communication approaches and more conventional mass screening approaches. In particular, there is a need to examine the issue of campaign sustainability and methods for maintaining public awareness, whereas avoiding campaign and message wear out - an issue identified by other researchers looking at similar behaviour change programmes (Smith et al, 2002).

\section{ACKNOWLEDGEMENTS}

The research is part of the West of Scotland Cancer Awareness Project funded by the New Opportunities Fund, now The Big Lottery Fund.

\section{Conflict of interest}

The authors declare no conflict of interest.
ISD Online, 2009 (2009) Information Services Division NHS Scotland, http:// www.isdscotland.org/isd/4680.html. Accessed 31 August 2009

Marino C, Gerlach KK (1999) An analysis of breast cancer coverage in selected women's magazines, 1987-1995. Am J Health Promot 13: $163-170$

Office for National Statistics (2009) Cancer Statistics Registrations. Registrations of Cancer Diagnosed in 2006

Pentz MA, Mihalic SF, Grotpeter JK (1997) Blueprints for Violence Prevention: Book One - The Midwestern Prevention Project. University of Colorado: Boulder, Colorado

Schoenbachler DD, Whittler TE (1996) Adolescent processing of social and physical threat communications. J Advert 25: 37-54

Schrijvers CTM, Mackenbach JP, Lutz JM (1995) Deprivation, stage at diagnosis and cancer survival. J Cancer 63: 324-329

Shelley JM, Irwig LM, Simpson JM, Macaskill P (1991) Evaluation of a mass-media-led campaign to increase Pap smear screening. Health Educ Res 6: $267-277$

Signorielli N (1990) Television and health: images and impact. In Mass Communication and Public Health Complexities and Conflicts, Atkin C, Wallack L (eds), Sage Publications: Newbury Park, California

Smith BJ, Ferguson C, McKenzie J, Bauman A, Vita P (2002) Impacts from repeated mass media campaigns to promote sun protection in Australia. Health Promot Int 17: 51-60

Social Trends No. 25. 1995 Edition (1995). Central Statistics Office: London Sugg-Skinner C, Strecher VJ, Hospers H (1994) Physicians' recommendations for mammography: do tailored messages make a difference? Am J Pub Health 84: 43-49

Sutton SM, Balch GI, Lefebvre RC (1995) Strategic questions for consumer-based health communications. Public Health Rep 110: $725-733$

Tanner JF, Hunt JB, Eppright DR (1991) The protection motivation model: a normative model of fear appeals. J Mark 55: 36-45

West R, Alkhatib MN, McNeill A, Bedi R (2006) Awareness of mouth cancer in Great Britain. Br Dent J 200: 167 - 169

Witte K, Berkowitz JM, Cameron KA, McKeon JK (1998) Preventing the spread of genital warts: using fear appeals to promote self-protective behaviors. Health Educ Behav 25: 571-585 